\title{
Lifestyle and Dietary Changes During Pregnancy among Attendees of Antenatal Care Clinics
}

\author{
Ghufran Jassim ${ }^{1 *}$, Randah R Hamadeh' ${ }^{2}$, Susan Dovey ${ }^{3}$ and Jamil Ahmed ${ }^{2}$ \\ ${ }^{1}$ Department of Family Medicine, Royal College of Surgeons in Ireland-Medical University of Bahrain \\ ${ }^{2}$ Department of Family and Community Medicine, Arabian Gulf University, Bahrain \\ ${ }^{3}$ Editor in Chief, Journal of Primary Health Care, Royal New Zealand College of General Practitioners \\ *Corresponding author: Ghufran Jassim, Department of Family Medicine, Royal College of Surgeons in Ireland-Medical University \\ of Bahrain
}

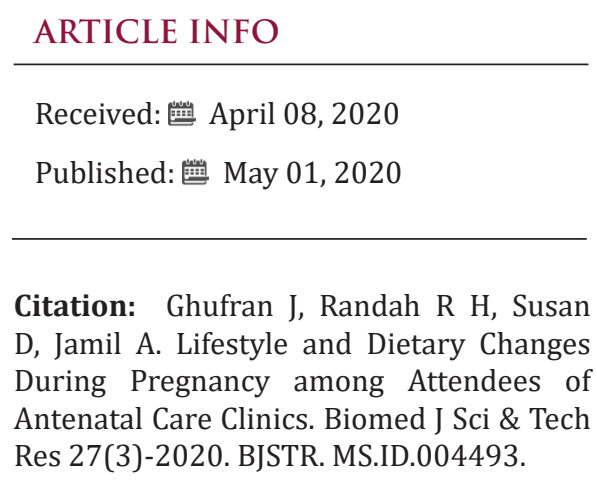

Keywords: Pregnancy; Lifestyle; Bahrain; Antenatal; Diet

\section{ABSTRACT}

Background: Women often make dietary changes during pregnancy but little is known of these dietary changes. We aimed to describe the dietary habits, knowledge and use of herbal remedies during pregnancy.

Methods: This is a cross sectional study in which 300 pregnant Bahraini women were recruited from primary health care centers in Bahrain.

Results: Two hundred and ninety nine responded and half reported good appetite with consumption of three meals daily. Most of the women knew about good dietary practice during pregnancy and believed that the type of food they consume can influence their pregnancy outcome $(86.0 \%$ and $74.7 \%$ respectively). The study found that $62.0 \%$ consumed fruits and vegetables daily and $35.0 \%$ consumed vegetables and fruits twice/weekly or less. Fish was consumed two times a week by $58 \%$, and once weekly or less by $15.0 \%$. One-third (30.6\%) disliked candies during pregnancy and $21 \%$ disliked eggs. Cinnamon was avoided by $69.0 \%$ of the participants and pineapple by $22.0 \%$. Only $17.2 \%$ reported using herbal remedies during pregnancy of which $51 \%$ used mint, 39\% green tea and 29\% ginger. The most common reason for using herbal remedies was to treat nausea and vomiting $(70.5 \%)$.

Conclusion: Pregnant Bahraini women are aware of the importance of maternal diet and its effect on the fetal outcomes. However, their dietary knowledge and practices are limited and not entirely compliant with international recommendations. Herbal remedy use was representative of the Bahraini culture and traditions and was often influenced by family and social media. Detailed nutritional assessment during pregnancy is recommended in future research.

\section{Introduction}

A healthy, balanced diet during pregnancy is essential to support optimal growth and development of the fetus and to meet the rapid and profound physiological changes from conception until birth. During pregnancy, the development of maternal tissues, fetal growth, and breast milk production increase nutritional requirements [1]. Deficiencies in key macronutrient and micronutrient can have a substantial impact on pregnancy outcomes and neonatal health [2]. Examples of micronutrients supplementation to prevent health outcomes are folic acid to prevent neural tube defects, iodine to prevent cretinism, zinc to reduce of preterm birth, and iron to reduce the risk of low birth weight [3]. Consumption of fast food and soft drinks have been associated with increased risk of gestational diabetes mellitus [4]. The Barker hypothesis proposed that adverse nutrition in early life, including prenatally increases susceptibility to the metabolic syndrome which includes obesity, diabetes, insulin insensitivity, hypertension, and hyperlipidemia and complications 
that include coronary heart disease and stroke [5]. Furthermore, a recent systematic review found an inverse association between the healthy dietary pattern and prenatal anxiety and depression scores [6].

Several international organizations advocate dietary recommendations and guidelines for pregnant women [1, 7]. However, the extent to which pregnant women abide with these guidelines is unknown. Changes in lifestyle behaviors around the time of pregnancy have been well described in the literature [8]. Some studies have described the use of herbal medicines during pregnancy, including research from the Middle East $[9,10]$. The prevalence of herbal use varied between regions and reached up to $82 \%$ in the Middle Eastern countries [10] compared to $26.7 \%$ in South West England [11] and 36\% in Australia [12]. With few exceptions, the beneficial and harmful effects of these herbal supplements remain inconclusive [13]. Therefore, it is deemed essential to describe the types of herbal remedies used and the reasons for which they are being used. Understanding pregnant women's dietary habits and level of knowledge of the nutrition and dietary requirements during pregnancy is important for guiding the development of effective approaches to support women in maintaining a healthy diet. Further, it is fundamental to promote and to prevent possible unhealthy behaviors during this short time sensitive window. This research aimed to build on existing knowledge and focus onthe dietary habits, practices and knowledge of Bahraini women during pregnancy.

\section{Methods}

\section{Design}

This cross-sectional survey was conducted with pregnant Bahraini women at any stage of their conception attending the antenatal clinics of primary health care centers as participants.

\section{Sample Size}

Based on the estimate of 5220 pregnant women attending the antenatal clinics at the health centers during 2018 [14], and with a $95 \%$ confidence level and $6 \%$ margin of error, 254 participants were needed to represent the population. However, we aimed to survey300 pregnant women to be certain that we obtained complete data for at least the required 254 .

\section{Sampling Method}

There are 28 health centers distributed in the five health governorates of Bahrain. We selected two health centers from each health region by simple random sampling. In each selected health center, 60 participants from the antenatal waiting area were invited to participate in the study. We used convenience sampling to identify the eligible participants. During the antenatal visit, women undergo checks of their vital health measures, and weight, and have obstetric examination.

\section{Measures}

We developed a survey instrument based on the tools used in the research we have identified, [15] related to each of the topics in our study. We also collected demographic data from participants. We piloted the survey on 50 participants who were not included in the study. The reliability of the questionnaire was tested and yielded a Cronbach alpha of 0.72 .

\section{Data Analysis}

The uni-variate analyses provided information on the prevalence of each lifestyle choice and are reported as frequencies and percentages. Chi square test was used to test the association between selected maternal knowledge items and sociodemographic variables. The selected items are: "I know about good dietary practice, the type of food influence pregnancy outcomes, poor maternal nutrition cause low birth weight". A P-value of $\leq 0.05$ was considered significant.

\section{Ethics}

We obtained ethical approval from the respective research committees of the Royal College of Surgeons in Ireland-Medical University of Bahrain, the Arabian Gulf University and the Bahrain Ministry of Health. We obtained patient oral consent and provided patient information sheet to all participants. Oral consent was deemed sufficient in light of the low risk nature of this study. The IRB approved this approach for the same reason. Oral consent was documented by data collectors in the survey.

\section{Results}

\section{Demographic Details}

Three hundred questionnaires were distributed and 299 responded yielding a response rate of $99.6 \%$. Mean (SD) age of participants was 30.0 (SD 5.7), median 29 years and range 29 (maximum 48.0 years, minimum 19.0 years). Women, on an average, had 1.45 (SD 1.37) children (Table 1).

\section{Maternal Dietary Habits and Nutritional Practices}

Over half of participants reported good appetite with consumption of three meals daily. The majority (60.0\%) consumed fruits and vegetables daily and only $40.6 \%$ consumed chicken or meat daily. Fish was consumed twice a week by $61.3 \%$ and once week or less by almost $15.0 \%$. Candy was the most disliked (30.6\%) during pregnancy followed by eggs (21.8\%). When asked about food item they would avoid during pregnancy, the majority chose cinnamon (69\%), pineapple (22\%), postpartum stew (made from garden cress seeds) (20\%) and saffron (16.9\%). All participants denied smoking and drinking alcohol during pregnancy (Table 2).

\section{Maternal Knowledge of Dietary Habits}

The participants identified family (43.3\%) and social media $(43.7 \%)$ as their main sources of information about dietary 
recommendations during pregnancy. Most of the women in our study believed that the type of food they consume can influence their pregnancy outcome and can result in low birth weight $(74.7 \%$ and $78.6 \%$, respectively). Most women agreed that smoking and drinking alcohol have harmful effects on the fetus $(97.7 \%$ and 98.3\%, respectively) (Table 3).

Table 1: Demographic characteristics of participants $(n=299)$.

\begin{tabular}{|c|c|c|}
\hline Variable & Frequency & $\%$ \\
\hline $\begin{array}{c}\text { Marital status } \\
\text { Married } \\
\text { Divorced } \\
\text { Widowed }\end{array}$ & $\begin{array}{c}285 \\
8 \\
6\end{array}$ & $\begin{array}{c}95.3 \\
2.7 \\
2.0\end{array}$ \\
\hline $\begin{array}{c}\text { Level of education } \\
\text { Illiterate } \\
\text { Elementary } \\
\text { Middle } \\
\text { Secondary/Diploma } \\
\text { Bachelor's degree and above }\end{array}$ & $\begin{array}{c}3 \\
3 \\
9 \\
145 \\
139\end{array}$ & $\begin{array}{r}1.0 \\
1.0 \\
3.0 \\
48.5 \\
46.5\end{array}$ \\
\hline $\begin{array}{c}\text { Employment } \\
\text { Working outside home } \\
\text { Retired } \\
\text { Housewife } \\
\text { Student }\end{array}$ & $\begin{array}{c}84 \\
4 \\
187 \\
23\end{array}$ & $\begin{array}{c}28.2 \\
1.3 \\
62.8 \\
7.7\end{array}$ \\
\hline
\end{tabular}

Table 2: Maternal dietary habits and nutritional practices.

\begin{tabular}{|c|c|c|}
\hline Variable & Frequency & $\%$ \\
\hline $\begin{array}{c}\text { Participant's appetite }(\mathbf{n}=\mathbf{2 9 8} \\
\text { Good } \\
\text { Reasonable } \\
\text { Low }\end{array}$ & $\begin{array}{c}162 \\
118 \\
18\end{array}$ & $\begin{array}{c}54.4 \\
39.6 \\
6.0\end{array}$ \\
\hline $\begin{array}{c}\text { No. of meals/day }(\mathbf{n}=\mathbf{2 9 8}) \\
\text { One meal/day } \\
\text { Two meals/day } \\
\text { Three meals/day } \\
\text { More than three meals/ day } \\
\text { It depends }\end{array}$ & $\begin{array}{c}5 \\
57 \\
180 \\
48 \\
8\end{array}$ & $\begin{array}{c}1.7 \\
19.1 \\
60.4 \\
16.1 \\
2.7\end{array}$ \\
\hline $\begin{array}{c}\text { Fruit/vegetable consumption(n= } \\
\text { Everyday } \\
\text { Three times/week } \\
\text { Twice/week } \\
\text { Once/week } \\
\text { Rare (less than once//week) }\end{array}$ & $\begin{array}{c}187 \\
6 \\
62 \\
18 \\
26\end{array}$ & $\begin{array}{r}62.5 \\
2.0 \\
20.7 \\
6.0 \\
8.7\end{array}$ \\
\hline $\begin{array}{c}\text { Meat/chicken consumption } \mathbf{n}= \\
\text { Everyday } \\
\text { Four times//week } \\
\text { Three times/week } \\
\text { Twicel/week } \\
\text { Oncel/week } \\
\text { Never }\end{array}$ & $\begin{array}{c}122 \\
59 \\
60 \\
55 \\
2 \\
2\end{array}$ & $\begin{array}{c}40.6 \\
19.7 \\
20.0 \\
18.3 \\
0.7 \\
0.7\end{array}$ \\
\hline
\end{tabular}




\begin{tabular}{|c|c|c|}
\hline \multicolumn{3}{|c|}{ Fish consumption $(n=287)$} \\
\hline Everyday & 7 & 2.1 \\
\hline Four times/week & 21 & 7.3 \\
\hline Three times/week & 37 & 12.9 \\
\hline Twice/week & 176 & 61.3 \\
\hline Once//Week & 11 & 3.8 \\
\hline Never & 36 & 12.5 \\
\hline \multicolumn{3}{|c|}{ Food disliked in pregnancy $(n=297)$} \\
\hline Fish & 49 & 16.4 \\
\hline Eggs & 65 & $2 \mathrm{p} 1.8$ \\
\hline Candy & 91 & 30.6 \\
\hline Fruits & 15 & 5.0 \\
\hline Vegetables & 12 & 4.0 \\
\hline others & 65 & 21.8 \\
\hline \multicolumn{3}{|l|}{ Food avoided $(n=295) a$} \\
\hline Cinnamon & 207 & 69.0 \\
\hline Tea & 12 & 4.0 \\
\hline Coffee & 32 & 10.7 \\
\hline Post-partum soupb & 60 & 20.0 \\
\hline Saffron & 50 & 16.9 \\
\hline Pineapple & 65 & 22.0 \\
\hline Papaya & 14 & 4.7 \\
\hline
\end{tabular}

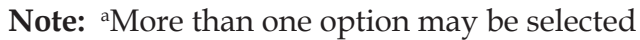

${ }^{\mathrm{b}}$ Made from garden cress seeds

Table 3: Knowledge of diet and other lifestyle factors in pregnant women attending ANC clinics.

\begin{tabular}{|c|c|c|}
\hline Statement & Frequency & $\%$ \\
\hline \multicolumn{3}{|c|}{$\begin{array}{l}\text { I know about good dietary practice during } \\
\text { pregnancy }(n=299)\end{array}$} \\
\hline Yes & 257 & 86.0 \\
\hline No & 42 & 14.0 \\
\hline \multicolumn{3}{|c|}{$\begin{array}{l}\text { I know about good dietary practices during } \\
\text { pregnancy froma }(n=298)\end{array}$} \\
\hline Family & 130 & 43.3 \\
\hline Friends & 36 & 12.0 \\
\hline Health care professionals & 82 & 27.5 \\
\hline Media & 61 & 20.3 \\
\hline Social media & 131 & 43.7 \\
\hline \multicolumn{3}{|c|}{ Women should eat more during pregnancy $(n=297)$} \\
\hline Yes & 95 & 31.7 \\
\hline No & 202 & 67.3 \\
\hline \multicolumn{3}{|c|}{$\begin{array}{l}\text { The type of food you eat during pregnancy have } \\
\text { influence on pregnancy outcome }(n=297)\end{array}$} \\
\hline Yes & 75 & 74.7 \\
\hline No & & 25.3 \\
\hline \multicolumn{3}{|c|}{$\begin{array}{l}\text { Poor Maternal nutrition cause low birth weight } \\
\text { baby and still birth?(n=295) }\end{array}$} \\
\hline Yes & 232 & 78.6 \\
\hline No & 63 & 21.4 \\
\hline
\end{tabular}




\begin{tabular}{|c|c|c|}
\hline $\begin{array}{c}\text { Smoking during pregnancy have harmful effects on } \\
\text { the baby(n=298) } \\
\text { Yes }\end{array}$ & 293 & 97.7 \\
No & 5 & 1.3 \\
\hline $\begin{array}{c}\text { Drinking alcohol during pregnancy have harmful } \\
\text { effects on the baby(n=297) }\end{array}$ & & \\
Yes & 292 & 98.3 \\
No & 5 & 1.7 \\
\hline
\end{tabular}

Note: aMore than one option maybe selected

\section{Pattern of Herbal Remedy Use}

In (Table 4) we summarize the pattern of using herbs among the participants. Only $17.2 \%$ women reported using herbs during pregnancy. About half of them (51.0\%) used mint, 39.0\% green tea and $29.0 \%$ ginger. Aniseed and Arabic gum were used to a lesser extent, $15.6 \%$ and $13.7 \%$ respectively. Participants who used herbal remedies did so by their own choice $(70.6 \%)$ or on the recommendation of their family $(76.4 \%)$. The most common reasons for using herbal remedy were nausea and vomiting $(70.5 \%)$, no pregnancy-related reason (66.6\%) and abdominal pain $(31.3 \%)$. Among those who used herbs $67 \%$ believed that they were effective in relieving the symptoms that they were used for.

\section{Association Between Maternal Knowledge And Sociode- mographic}

The association between selected items on the maternal knowledge questionnaire and sociodemographic data is presented in (Table 5). A Chi square test of independence was calculated and a significant interaction was found between "women should eat more during pregnancy" and categories of education (P-value=0.033) and employment (P-value=0.008). Further, a significant interaction was found between "Type of food influence pregnancy outcomes" and education (P-value<0.000) and employment (P-value=0.004) categories.

Table 4: Use of Herbs among participants.

\begin{tabular}{|c|c|c|}
\hline Statements & Frequency & $\%$ \\
\hline $\begin{array}{l}\text { I use herbs during pregnancy }(\mathbf{n}=\mathbf{2 9 6}) \\
\text { Yes } \\
\text { No }\end{array}$ & $\begin{array}{c}51 \\
245\end{array}$ & $\begin{array}{l}17.2 \\
82.8\end{array}$ \\
\hline $\begin{array}{c}\text { Types of herbs used }{ }^{\mathrm{a}}(\mathbf{n}=\mathbf{5 1}) \\
\text { Ginger } \\
\text { Mint } \\
\text { Fenugreek } \\
\text { Green tea } \\
\text { Garlic } \\
\text { Aniseed } \\
\text { Arabic gum }\end{array}$ & $\begin{array}{c}12 \\
26 \\
5 \\
20 \\
7 \\
8 \\
7\end{array}$ & $\begin{array}{c}29.4 \\
50.9 \\
9.8 \\
39.2 \\
13.7 \\
15.6 \\
13.7\end{array}$ \\
\hline $\begin{array}{l}\text { People who recommended use of herbs* }(\mathbf{n}=\mathbf{5 1}) \\
\qquad \begin{array}{c}\text { Myself } \\
\text { Family } \\
\text { Friends } \\
\text { Healthcare workers }\end{array}\end{array}$ & $\begin{array}{l}36 \\
39 \\
13 \\
10\end{array}$ & $\begin{array}{l}70.6 \\
76.4 \\
25.4 \\
19.6\end{array}$ \\
\hline
\end{tabular}

Note: aMore than one option maybe selected

Table 5: Association between selected maternal knowledge items and sociodemographic data.

\begin{tabular}{|c|c|c|c|}
\hline \multirow{2}{*}{ Variable } & \multicolumn{2}{|c|}{ I know about good dietary practice during pregnancy } \\
\cline { 2 - 4 } & Yes & \multicolumn{2}{|c|}{ No } \\
\hline Marital status & $245(95.3 \%)$ & $40(2.4 \%)$ & P-value \\
Married & $7(2.7 \%)$ & $1(2.4 \%)$ & 0.975 \\
Divorced & $5(1.9 \%)$ & $1(2.4 \%)$ & \\
Widow & & \\
\hline
\end{tabular}




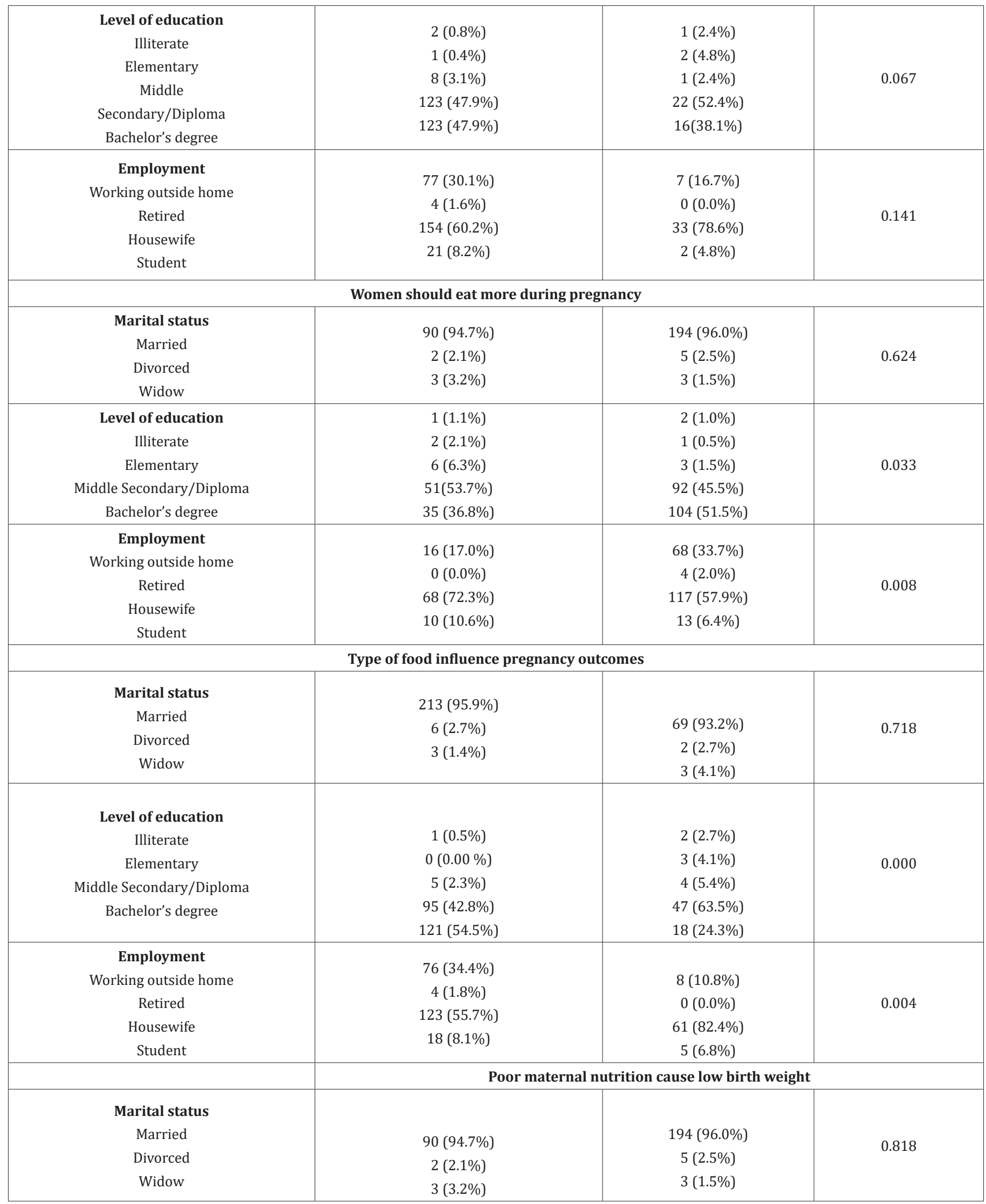




\begin{tabular}{|c|c|c|c|}
\hline Level of education & $1(0.4 \%)$ & $2(3.3 \%)$ \\
Illiterate & $1(0.4 \%)$ & $1(1.6 \%)$ & $2(3.3 \%)$ \\
Elementary & $7(3.0 \%)$ & $32(52.5 \%)$ & $24(39.3 \%)$ \\
Middle Secondary/Diploma & $109(47.0 \%)$ & $17(27.9 \%)$ & $1(1.6 \%)$ \\
Bachelor's degree & $114(49.1 \%)$ & $40(65.6 \%)$ & 0.615 \\
\hline Employment & $66(28.6 \%)$ & $3(4.9 \%)$ & 0.953 \\
\hline Working outside home & $3(1.3 \%)$ & \\
Retired & $142(61.5 \%)$ & $20(8.7 \%)$ & \\
\hline Sousewife & & \\
\hline
\end{tabular}

\section{Discussion}

To our knowledge, this is the first study describing Bahraini women's pregnancy-specific dietary habits and beliefs. This study shows that pregnant women are poorly adherent to the international dietary guidelines. Notably, their intake of protein, fruits and vegetables were below the recommended daily requirement which is estimated to be $60 \mathrm{~g} /$ day of protein and 3 to 4 portions/day of fruits and vegetables [1]. About 16\% disliked fish and $70 \%$ reported consuming fish twice weekly or less, thereby missing out its nutritional benefit for the fetus. Similar results were reported in international studies [16]. Fish is rich in Vitamin D and omega-3 fatty acids that are important for the development of a fetus's brain, eyes, and nervous system [17]. The recommendation is to eat 2 to 3 servings per week [18]. Although fish such as shark, tuna and swordfish are not advised because of their high mercury content, [18] we did not inquire about types of fish in our study but about eating fish in general.

When they were asked about food they would avoid during pregnancy, our participants were mostly focused on food that might increase their risk of miscarriage. It is concerning that women did not include food that is a rich source of vitamin A (such as liver) or raw uncooked food as food to avoid during pregnancy despite their well-documented harmful effect on the fetus [19, 20]. Instead, they mentioned cinnamon and pineapple as two main avoided items because they were perceived as risk factors for miscarriage. Similar results of avoiding cinnamon and pineapple were reported in a study from Saudi Arabia [21]. Scientific evidence regarding the benefits and harms of cinnamon and pineapple is either lacking, inconclusive [22] or negligible [23]. Further, the uterine stimulant theory of these products and the belief that they induce abortion or labor does not specify the amount that should be consumed to see the harmful or beneficial effect [23]. This is an area that needs definitive research to support or refute widespread beliefs in Bahrain. In concordance with the published literature, [16] pregnant women recognize that a healthy, balanced diet and healthy life style are "important" to fetal health and are more likely during their pregnancy to be mindful of nutrition and life style habits. This was reflected in that the majority agreed that maternal diet affects fetal outcomes and that almost all participants refrained from smoking and drinking alcohol and agreed on their harmful effect on the fetus.

Often, family and social media were the sources of information our participants used. The same has been documented in other Middle Eastern studies [10]. This reflects the influence of social media, which contains many articles advertising and promoting non-evidence-based dietary practices [10]. It also implies the importance of including the family in any dietary and lifestyle interventions in this part of the world. The most popular herbs used in our study were mint, green tea, ginger, aniseed and Arabic gum, which is very similar to what has been reported in studies from this region [10]. In agreement with other studies, the herbs were mostly used to treat the bothersome symptoms of nausea and vomiting [10]. However, only $17.0 \%$ of the study participants admitted using herbal remedies during pregnancy. This percentage is reversed in the Saudi study where about two thirds of women used herbal products [21]. One should be cautious interpreting this finding because women might not consider some products they habitually use as herbal remedies. In general, herbal supplementation is complex, vaguely defined in the literature and there is confusion on what it constitutes [25]. Ginger is the only well-established herbal product as an effective treatment for nausea and vomiting [26]. However, ginger was used by only one third of participants who admitted to using herbal remedies.

Factors influencing maternal knowledge in this study were education and employment. This is in agreement with other international studies $[27,28]$. One should note that majority of these studies were conducted in underdeveloped parts of the world with limited resources which makes the comparison rather unfair. Other well document influential factors reported in these studies were family income and husband support. Both of which were not among the variables studied in this research. This study exploring the dietary habits and use of herbal remedies among pregnant women in Bahrain, sets the foundation for establishing national dietary guidelines during pregnancy and will drive future research. This will set the foundation for establishing dietary guidelines during pregnancy and will drive future research. Although this is an important study of the diets of pregnant Bahraini women and was designed with attention to sample size so that it can be generalized 
to all Bahraini women, only about half of the country's residents are Bahraini. We make no claim to represent the diets and health beliefs of pregnant women of other cultures who live in Bahrain. Also, although the study clinics were randomly selected, we used convenience sampling to enroll participants from within the sampled clinics and this may have biased the study in the direction of including women who attend more carefully to their health. Our survey lacked detailed nutritional questions relating to number of servings, standard serving size and nutrient content of certain food. Further, the survey did not allow for an overall knowledge score to be calculated and hence used for analysis. This limited our ability in conducting further bivariate and multivariate analyses.

We recommend that health care providers play a greater role in educating pregnant women regarding the recommended dietary habits and screening women for non-prescribed supplements and herbal remedy use. Further research is needed to explore the detailed nutritional content of maternal diet and prescribed and non-prescribed supplements.

\section{Conclusion}

Women are aware of the importance of their diet during pregnancy and its effect on fetal outcomes. However, their knowledge and dietary practices are limited and not entirely compliant with international recommendations. Herbal remedies use was representative of the culture and traditions and was often influenced by family and social media.

\section{Acknowledgement}

We would like to thank all participants for their participation. Further, sincere thanks go to the students of the Royal College of Surgeons in Ireland-Medical University of Bahrain (Nazha AlFaraj, Moshira Mahran, Wissal Aknouche, Maryam Jameel) for their help with data collection and entry. The thanks is also extended to Arabian Gulf University students (Hussain AlAradi and Mariam AlSalem) for their assistance with data collection.

\section{Disclosure of Interest}

The authors report no conflict of interest.

\section{References}

1. Marangoni F, Irene Cetin, Elvira Verduci, Giuseppe Canzone, Marcello Giovannini, et al. (2016) Maternal Diet and Nutrient Requirements in Pregnancy and Breastfeeding. An Italian Consensus Document. Nutrients 8(10): 629

2. Mousa AA, Naqash, S Lim (2019) Macronutrient and Micronutrient Intake during Pregnancy: An Overview of Recent Evidence. Nutrients $11(2)$.

3. Gernand AD, Kerry J Schulze, Christine P Stewart, Keith P West (2016) Micronutrient deficiencies in pregnancy worldwide: health effects and prevention. Nature reviews. Endocrinology 12(5): 274-289.

4. Dominguez LJ, Miguel A, Martínez González, Francisco Javier BasterraGortari, Alfredo Gea, et al. (2014) Fast food consumption and gestational diabetes incidence in the SUN project. PloS one 9(9): e106627-e106627.
5. Edwards M (2017) The Barker Hypothesis. In: Preedy V Patel V (Eds.). Handbook of Famine Starvation and Nutrient Deprivation. Springer, Cham.

6. Silva DFO, Ricardo Ney Cobucci, Ana Katherine Gonçalves, Severina Carla Vieira, Cunha Lima et al. (2019) Systematic review of the association between dietary patterns and perinatal anxiety and depression. BMC Pregnancy and Childbirth 19(1): 212

7. Ortega RM, (2001) Dietary guidelines for pregnant women. Public Health Nutr 4(6a): 1343-1346.

8. O Keeffe LM, Darren L Dahly, Marion Murphy, Richard A Greene, Janas M Harrington et al. (2016) Positive lifestyle changes around the time of pregnancy: A cross-sectional study. BMJ open 6(5): e010233-e010233.

9. Pallivalappila AR, Derek Stewart, Ashalatha Shetty, Binita Pande, James S McLay et al. (2013) Complementary and Alternative Medicines Use during Pregnancy: A Systematic Review of Pregnant Women and Healthcare Professional Views and Experiences. Evidence-Based Complementary and Alternative Medicine p. 10.

10. John LJ, N Shantakumari (2015) Herbal Medicines Use during Pregnancy: A Review from the Middle East. Oman Med J 30(4): 229-236.

11. Bishop JL (2011) The use of Complementary and Alternative Medicine in pregnancy: data from the Avon Longitudinal Study of Parents and Children (ALSPAC). Complement Ther Med 19(6): 303-310.

12. Forster DA, Angela Denning, Gemma Wills, Melissa Bolger, Elizabeth A Mccarthy, et al. (2006) Herbal medicine use during pregnancy in a group of Australian women. BMC Pregnancy Childbirth 6: 21.

13. Ahmed M, Jung Hye Hwang, Soojeung Choi (2017) Safety classification of herbal medicines used among pregnant women in Asian countries: A systematic review. BMC complementary and alternative medicine 17(1): 489-489.

14. (2016) MOH. Health statistics.

15. O Keeffe LM, Darren L Dahly, Marion Murphy, Richard A Greene, Janas M Harrington, et al. (2016) Positive lifestyle changes around the time of pregnancy: A cross-sectional study. BMJ Open 6(5): p. e010233.

16. Bookari KH, Yeatman, M Williamson (2016) Exploring Australian women's level of nutrition knowledge during pregnancy: A crosssectional study. International journal of women's health 8: 405-419.

17. Hibbeln JR, John M Davis, Colin D Steer, Pauline M Emmett, Imogen S Rogers, et al. (2007) Maternal seafood consumption in pregnancy and neurodevelopment outcomes in childhood (ALSPAC study): An observational cohort study. Lancet 369(9561): 578-585.

18. Taylor CM (2018) A review of guidance on fish consumption in pregnancy: Is it fit for purpose? Public health nutrition 21(11): 21492159.

19. Azais Braesco V, G Pascal (2000) Vitamin A in pregnancy: Requirements and safety limits. Am J Clin Nutr. 71: 1325s-1333s.

20. Tam C, A Erebara, A Einarson (2010) Food-borne illnesses during pregnancy: prevention and treatment. Canadian family physician Medecin de famille canadien 56(4): 341-343.

21. Mohammed Aljoher A, M Abdullah Alsaeed, M Abdulltife Alkhlfan (2018) Pregnant Women Risk Perception of Medications and Natural Products Use during Pregnancy in Alahsa, Saudi Arabia. The Egyptian Journal of Hospital Medicine 70: 13-20.

22. Abraham K, Friederike Wöhrlin, Oliver Lindtner, Gerhard Heinemeyer, Alfonso Lampen, et al. (2010) Toxicology and risk assessment of coumarin: Focus on human data. Mol Nutr Food Res 54(2): 228-39.

23. Monji F, Ganesan Adaikan, Lang Chu Lau, Baharudin Bin Said, Yinhan Gong, et al. (2016) Investigation of uterotonic properties of Ananas comosus extracts. Journal of Ethnopharmacology 193: 21-29. 
24. Westerman D, PR Spence, B Van Der Heide (2014) Social Media as Information Source: Recency of Updates and Credibility of Information Journal of Computer-Mediated Communication 19(2): 171-183.

25. Chang J (2000) Medicinal herbs: Drugs or dietary supplements? Biochemical Pharmacology 59(3): 211-219.

26. Lete I, J Allué, (2016) The Effectiveness of Ginger in the Prevention of Nausea and Vomiting during Pregnancy and Chemotherapy. Integrative medicine insights 11: 11-17.

ISSN: $2574-1241$

DOI: 10.26717/BJSTR.2020.27.004493

Ghufran Jassim. Biomed J Sci \& Tech Res

(C) $(1)$ This work is licensed under Creative

Submission Link: https://biomedres.us/submit-manuscript.php
27. Daba G (2013) Assessment of Knowledge of Pregnant Mothers on Maternal Nutrition and Associated Factors in Guto Gida Woreda, East Wollega Zone, Ethiopia. Journal of Nutritional Disorders \& Therapy.

28. Oh HK, Sunjoo Kang, Sung Hyun Cho, Yeongju Ju, Daouda Faye, et al. (2019) Factors influencing nutritional practices among mothers in Dakar, Senegal. PloS one 14(2): e0211787-e0211787.

$\begin{array}{ll}\text { BIOMEDICAL } & \text { Assets of Publishing with us } \\ \text { RESEARCHES } & \text { - Global archiving of articles } \\ \text { - Immediate, unrestricted online access }\end{array}$

